\title{
Huellas de una pérdida / Huellas de un poder. El fenómeno de los lugares para la conmemoración
}

\section{Traces of a loss / Traces of power. The phenomenon of places for commemoration}

\section{<Resumen>}

¿Cómo se relacionan monumentos y memoriales con los procesos de creación de la memoria colectiva y por tanto con la historia futura? ¿Desde dónde surgen los actuales paradigmas y las nuevas respuestas respecto a ellos?

El presente documento busca indagar en las bases sociales y materiales de estos espacios conmemorativos así como en aquellas propuestas que reconceptualizan la idea de conmemoración

$<$ Abstract $>$

How do monuments and memorials relate with the creation processes of collective memory and therefore history-making? Where do the current paradigms and new answers emerge from?

The present document seeks to inquire about these memorials, as well as those proposals that re-conceptualize the idea of commemoration.

$<$ PALABRAS CLAVE >

MONUMENTO / MEMORIAL / ANTIMONUMENTO / ANTIMEMORIAL / MEMORIA COLECTIVA / PODER / EVENTO / MEMENTO

\section{KKEYWORDS>}

MONUMENT / MEMORIAL, ANT I-MONUMENT / COUNTERMEMORIAL / COLLECTIVE MEMORY / POWER / EVENT / MEMENTO
"La ciudad es el centro de la memoria colectiva».

Aldo Rossi ${ }^{1}$

\section{Introducción}

Cuando observamos nuestras ciudades es prácticamente imposible no reparar en la presencia de diferentes épocas, tiempos y/o eventos que se dibujan sobre ellas. Algunos de estos trazos son sólo arrugas naturales que se disfrazan como edificio antiguo, un puente añoso o una nostálgica rivera. Algunas otras, en cambio, son construcciones nuevas con referencia en eventos pasados como método para materializar la historia y el recuerdo, así como también para perpetuar un mensaje en particular hacia el futuro. Comúnmente llamamos a este segundo tipo de huellas como espacios conmemorativos, y particularmente como monumento y/o memorial ${ }^{2}$

El propósito de este ensayo será el explora tales espacios para la conmemoración. Específicamente, me concentraré en el tipo de memoriales que surgen como respuesta a eventos traumáticos específicos, con un fuerte contenido político y en los cuales memorias y recuerdos dolorosos se ven convocados. Lugares dedicados a recordar «...eventos traumáticos en los que se han perdido muchas vidas y en los cuales los intentos por encontrar un significado se han visto estresados por el

Arquitecta (Distinción Máxima), Universidad de Chile 2005. MA ISD - Master of Arts Interior and Spatial Design (Distinción) Chelsea College of Arts, University of the Arts London 2007, Inglaterra. En la actualidad desarrolla labores docentes en Chelsea College of Arts, University of the Arts London (MA ISD) y University College for the Creative Arts at Canterbury (BA Interior Architecture), Inglaterra.

Aldo Rossi. L'Architettura della citta. Padua: Marsilio Editori, 1966; III. En: Sebastien Marot. Sub-urbanism and the art of memory. Londres: AA, 2003; p. 32 (traducción libre del autor).

2 En páginas siguientes se profundizará en los conceptos de monumento y memorial. 
duelo» ${ }^{3}$. Muy probablemente algunos de los mejores ejemplos respecto a lo que nos ocupa son: memorias en relación con un cambio de poder en lo ideológico/político, memorias en conexión con un abuso de poder y finalmente aquellas memorias relacionadas con ataques terroristas. A su vez, los límites entre una y otra de estas tipologías tienden siempre a desdibujarse; un cambio ideológico/político puede involucrar y/o evolucionar en un abuso de poder y viceversa, así como un poder abusivo puede involucrar y/o evolucionar en un ataque terrorista. Pero, bajo cualquiera de los casos anteriores, lo que permanece intacto es el sentido de trauma, desolación, injusticia e inquietud social generados por estos eventos y la manera de conmemorarlos. Este es el ámbito en el cual aparecen los lugares que conciernen a esta presentación.

La estructura de este documento será la siguiente: en la primera parte explicaré porqué la naturaleza intrínseca de memoriales y monumentos puede ser comprendida como perversa. Trataré de aclarar algunos ideas básicas respecto a un campo saturado de asuntos políticos, sociales e incluso sentimentales y sus peligros -creo que sin esta plataforma teórica las preguntas que han ido alimentando mi investigación y mi práctica no hubiesen evolucionado nunca-. La segunda parte será desde un enfoque más concreto y fáctico hacia el fenómeno, donde contextualizaré mi trabajo en relación con proyectos de otros artistas y arquitectos -explorando las distintas formas que eligieron para responder a algunos de los asuntos que aparecen en la parte primera y explicando mi postura personal a su respecto y el cómo esto se ve reflejado en mi propia práctica-.

Intentaremos cuestionar cómo estos espacios conmemorativos se ven envueltos en el proceso de hacer historia y cómo -al insertarse en nuestras ciudades- pueden ser parte de la creación de una memoria colectiva en particular en donde la negociación entre el sentido individual de pérdida y la respuesta pública a ella están en tensión constante. Analizará también qué sucede hoy en día cuando: la contingencia, la instantaneidad y el desarrollo masivo de los medios de información, junto con la fuerte lucha por mantener al mundo en «democracia», generan nuevos dilemas en el diseño, análisis y vivencia de estos espacios públicos para la memoria y la información.

Finalmente, es importante mencionar que este texto es parte esencial del desarrollo de mi proyecto en memoria de los detenidos desaparecidos bajo la dictadura de Pinochet. Hoy, desde mi perspectiva arquitectónica y artística, estoy interesada en el acercamiento espacial-material al tema.

\section{La esencia perversa del memorial}

Comenzaré con plantear lo que me gusta denominar como «la esencia perversa del memorial». Esto es, básicamente: la doble aptitud del memorial para por un lado encarnar un sentido colectivo de luto ante una pérdida irreparable y por otro lado el ser herramienta para compensar/reparar tal pérdida -como técnica de redención por parte de algún pode jerárquico-. Tradicionalmente el monumento ha sido el recurso espacial principal para la conmemoración, y es justamente aquella la raíz de esta esencia perversa del memorial; que puede con mucha facilidad hacerse monumental.

Para Lefevre, esa posible monumentalidad crearía un "espejo colectivo» oficial de una sociedad en particular, en donde:

«... bajo las condiciones de un Poder aceptado de manera general y de un Saber aceptado de manera general... El elemento de represión con el de exaltación pueden apenas distinguirse; o quizás sería más preciso decir que el elemento represivo es metamorfoseado en exaltación» ${ }^{4}$.

James E. Young, tomando en consideración el entretejimiento de monumento y memorial, menciona:

"La matriz de los monumentos de una nación emplea el relato de eventos ennoblecedores, de triunfos sobre el barbarismo, y recuerda el martirio de aquellos quienes dieron sus vidas en la lucha por la existencia nacional -quienes, según el dicho con martirio como lógica, murieron para que el país pudiese vivir- ${ }^{5}$. En el asumir las formas idealizadas y significados asignados por el Estado, los memoriales tienden a concretizar interpretaciones históricas específicas... y tal memoria idealizada existe tan natural para el ojo como e paisaje en el cual se levanta» ${ }^{6}$

Ambas citas aluden a lo que es característico de tales situaciones espaciales: «metamorfosean el elemento represivo en exaltación», y básicamente «tienden a concretizar interpretaciones históricas específicas». O más simplemente; eliminan futuras preguntas y reflexiones respecto algún evento, moldeando respuestas eternas e imponiendo significados constantes. Es así como se levantan hitos, se potencian grandes avenidas y se tematizan plazas y parques. Se monumentaliza la ciudad.

Me gustaría aquí hacer una pequeña pausa en la teoría para explicar porqué es extremadamente importante plantear estas ideas. En Chile, los gobiernos junto a otras instituciones, han comenzado a fomentar concursos y proyectos para conmemorar a las víctimas del régimen militar -el «mundo de las artes» así como también el de los familiares afectados lo había planteado con anterioridad pero hasta ahora siempre se habían encontrado con marginalidad-. Personalmente creo que una cosa es comenzar a diseñar y promover el levantamiento y creación de estos sitios, pero otra completamente diferente es fomentar la discusión sobre cómo estos lugares debieran de ser; en el sentido más inclusivo de la pregunta. Y aquella discusión, a no ser secretamente, no está sucediendo. En consecuencia, el riesgo está en replicar lo que es el Memorial Nacional para los Detenidos Desaparecidos en el Cementerio General: un gran muro de piedra grabado con nombres. ¿Qué está representando ese memorial? Un típico memorial de guerra ¡cuando no existió guerra alguna!, en el lugar oficial para enterrar los cuerpos y recordar a seres queridos ¡cuando en realidad no hay cuerpos que enterrar! En el mejor de los casos, si no es este el ejemplo a seguir, probablemente la tendencia se dirigirá a lo que ya se conoce como una «nueva respuesta tipo»: la agrupación de elementos seriados, el simbolismo de un ícono repetido tantas veces como desaparecidos a recordar. Para evitar este tipo de respuestas «express» es que es relevante plantear esta discusión.

\footnotetext{
Marita Sturken. Tangled memories, Londres: University of Californa Press, 0000; p. 2 (traducción libre del autor).

Henri Lefebvre. The production of space. Oxford: Blackwell, 1991; p. 220 (traducción libre del autor).

Axioma utilizado ampliamente por entidades de poder como justificación ante la aplicación de medidas represivas.

Axioma utilizado ampliamente por entidades de poder como justificación ante la aplicación de medidas repres
James E. Youg. The texture of memory. Londres: Yale University Press, 1993; p. 2 (traducción libre del autor).
} 
El ojo de la imaginación. Autor: Robert Fludd, 1619.

Fuente: Sébastien Marot. Sub-urbanism and the Art of Memory. Londres: AA, 2003.

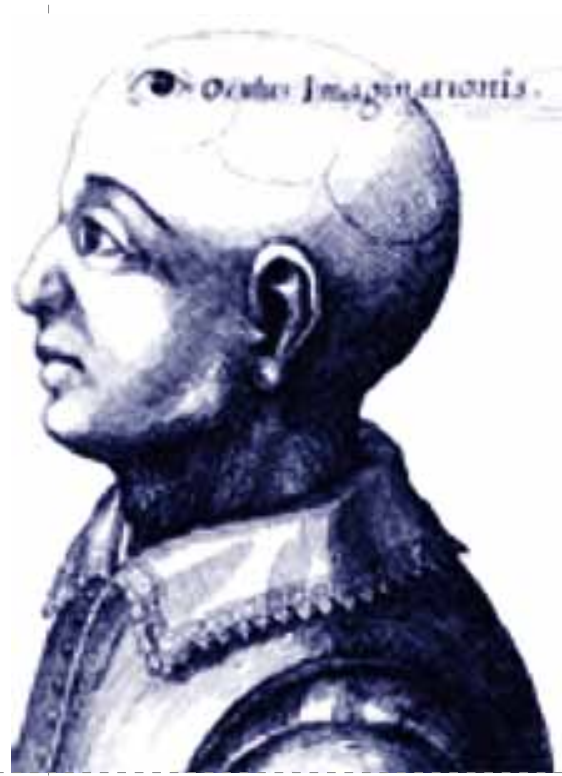

Como se ha mencionado con anterioridad, una característica de estos lugares para la conmemoración es que forman parte de la esfera pública. Siempre estarán bajo el dominio de lo público, estableciendo una armonía aparente en la vida social a través de la materialización de un tipo específico de remembranza. Son, por definición, piezas de narrativa pública. De acuerdo con Kirk Savage el significado de la palabra conmemoración puede entregarnos algunas claves sobre esto:

\section{«... el conmemorar es 'llamar a la} remembranza', marcar un evento o a una persona o a un grupo a través de alguna ceremonia o algún ritual, o a través de la observación de un monumento de algún tipo.. el punto clave está en que se actúa sobre la memoria colectiva de manera evidente» ${ }^{7}$.

Actuarán sobre lo que es el cuerpo cultural y social de recuerdos; lo que llamamos memoria colectiva8. Maurice Halbwachs -quien desarrolló el concepto de memoria colectiva en contraste con la idea de una memoria atada o limitada como la propuesta por Freudargumentó que la memoria no es una cápsula impermeable a estímulos externos; si no que es más un umbral que absorbe la realidad y los cambios de su contexto reaccionando a ellos a través de diferentes procesos de reconstrucción, en donde la mayor influencia está dada por el marco social. Planteó la idea de mutabilidad en la memoria, estando ésta siempre bajo la influencia de «lo exterior», y una de las partes más evidentes de lo exterior es la dimensión espacial; y en su contexto contemporáneo, la ciudad. Esta esfera -puesto que no podemos jamás eludirla- jugará un rol concomitante en el atributo cambiante de la memoria colectiva. En palabras de Halbwachs:

«... la memoria colectiva encuentra su base fundacional en imágenes espaciales... Así, no hay memoria colectiva que no se despliegue en un marco de control espacial» ${ }^{9}$.

Y son estos espacios de conmemoración la tipología más representativa de ese marco de control espacial. Más adelante, Foucault -tomando en consideración a Halbwachsargumenta:

"Ya que la memoria es verdaderamente un importante generador de luchas (de verdad, de hecho, luchas que se desarrollan como maneras conscientes de avanzar o mover la historia), si uno controla la memoria de la gente, uno controla su dinamismo» ${ }^{10}$

Bajo tal contexto, lo que la gente recuerda y/o lo que la gente olvida, es susceptible a ser manipulado. Y cuando hablamos sobre cómo conmemorar eventos dolorosos donde un grupo considerable de personas o incluso una nación ha sido victimizada, este es un asunto especialmente sensible -ya que lo guardado en sus memorias afectará el entendimiento de ellas en sí mismas, su sentido de historia y su relación con otros-. Marita Sturken en su libro «Tangled Memories» menciona:

«... La memoria provee el corazón mismo de la identidad... El recuerdo colectivo de una cultura específica puede parecer, frecuentemente, similar a la memoria de un individuo, provee identidad cultural y le entrega un sentido de importancia al pasado. Todavía más, el proceso de memoria cultural está envuelto por complejas ideas políticas y significados» ${ }^{11}$

Además de esta transmutación política, hay al menos otra fuerza trabajando en estos espacios de conmemoración, el poder de la permanencia, de transformar el pasado en un presente perpetuo, puesto que usualmente son estructuras rígidas enseñando «el» y «su» poder a través de la abolición de la muerte, trascendiendo el ciclo natural de la vida. En palabras de Lefebvre:

"La monumentalidad trasciende a la muerte, y por lo tanto también lo que a veces es llamado como 'instinto de muerte'. Como ambos, apariencia y realidad, esta trascendencia se incrusta como la fundación irreducible del monumento; la característica de temporalidad se ve abrumada por la ansiedad, incluso -y de hecho por sobre todo- en monumentos funerarios... un monumento transmuta el miedo por el paso del tiempo, y la ansiedad por la muerte, en esplendor... La monumentalidad reemplaza una realidad brutal con una apariencia materialmente realizada. Lo imperecedero de lo monumental tiene el sello del deseo por poder»12.

Kirk Savage. History, memory and monuments: An overview of the scholarly literature on commemoration. Ensayo online comisionado por Organization of American Historians at the National Park Service, en: [http://www.cr.nps.gov/history/resedu/savage.htm] (traducción libre del autor).

En este documento se utilizará el concepto de memoria colectiva según el sociólogo francés Maurice Halbwachs.

Maurice Halbwachs. Les cadres sociaux de la mémoire. París: Albin Michel, 1994; p. 200. En: Sebastien Marot. Sub-urbanism and the art of memory. Londres: AA, 2003; p. 30 (traducción libre del autor).

Michael Foucault. Film and popular memory: An interview with Michael Foucault. Radical Philosophy, 1975; p. 25 (traducción libre del autor).

1 Marita Sturken. Tangled memories. Londres: University of California Press, 1997; p. 1 (traducción libre del autor).

12 Lefevre. Op. cit.; p. 221 (traducción libre del autor). 
Monumento Nacional ciudad de Oklahoma. Autor: David Leeson. Fuente: www.time.com/time/photoessays/memorial/1.html

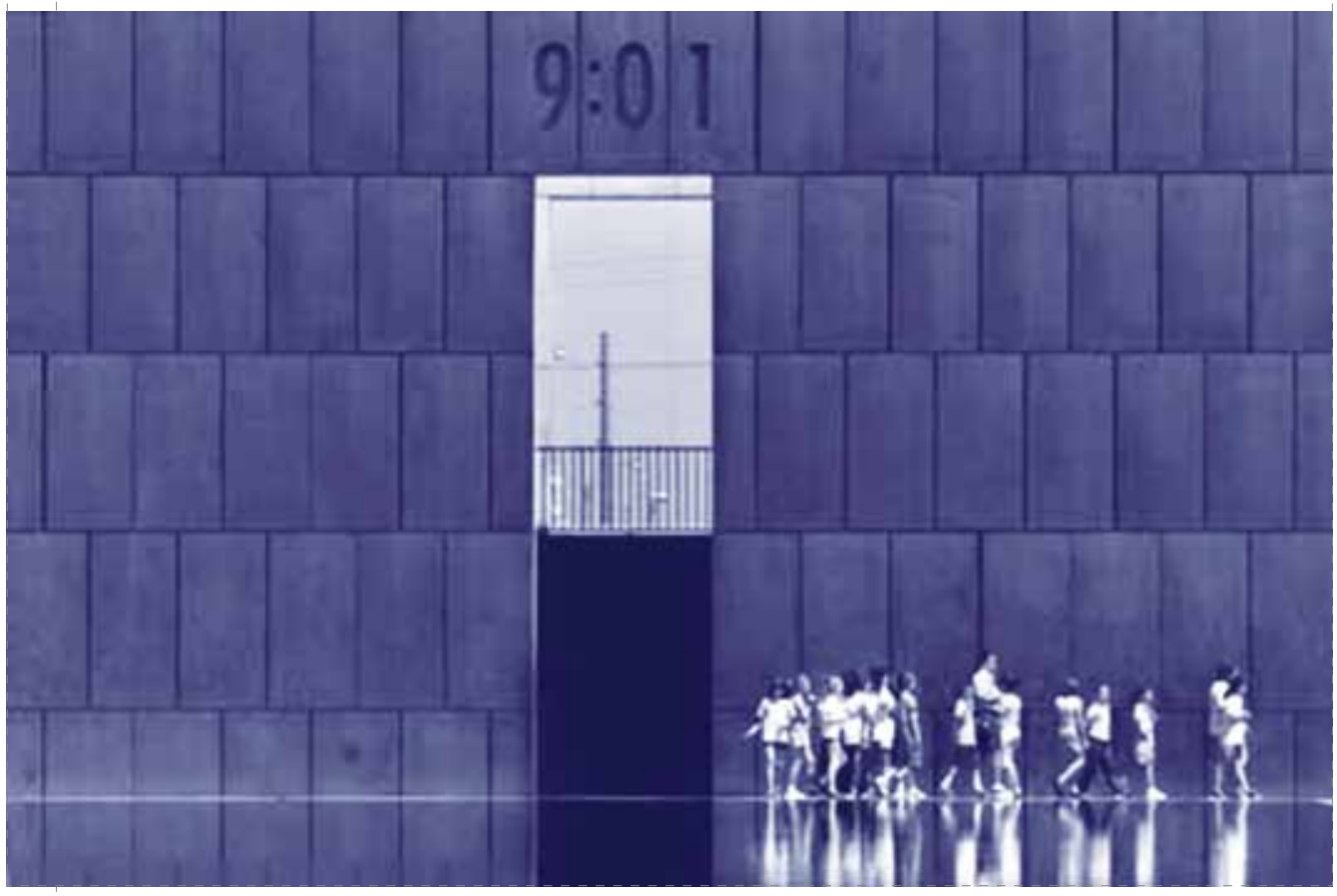

De hecho, muchos países tienen entidades a cargo de la correcta preservación de sus memoriales y monumentos, y éstas se concentran, en general, en evitar las marcas del paso del tiempo sobre ellos. Tienen que mantener estos espacios para la «memoria» apartados de la vida ocurrente, lo que finalmente significa fijar los significados, eludir la memoria.

En cierta forma, la naturaleza de estos lugares conmemorativos es extremadamente violenta -no sólo porque evoquen eventos brutales como muertes masivas, sino que también por su imposición al cómo comprender un evento en particular-; su rigidez para plantear conclusiones colectivas. Incluso cuando hablamos sobre un suceso reciente estos espacios tienden a remplazar el sentido personal de pérdida por alguna compensación social jerárquica. Kirk Savage escribe en relación con el diseño del Memorial Nacional de la Ciudad de Oklahoma13.
«... Los monumentos se encuentran en el ápice del dilema. El didacticismo tradicional que invoca nociones de sacrificio ante una causa noble niega la situación real de la víctima y por lo tanto viola la 'verdad' de la experiencia traumática» ${ }^{14}$

\section{Rompiendo paradigmas}

Mi pelo se ha vuelto cano.

Mis ojos tristes y cansados.

Tantas lágrimas han sido derramadas en estos años pasados.

Dejo la pregunta

¿Volveré a verle algún día?

IRMA MuLleR ${ }^{15}$

Hoy en día -en relación con el desarrollo masivo de los medios de comunicación y el consecuente proceso de globalización, así como el sentido de simultaneidad e instantaneidad que caracterizan nuestros tiempos y promueven una cultura de la ansiedad en donde los eventos están siendo conmemorados prácticamente en el momento en que suceden, incluso en distintas partes del mundo- el acercamiento ideológicamente prevalente hacia el fenómeno de la conmemoración (la esencia perversa del memorial) y por tanto su configuración espacial en el tejido ciudad parecen estar enfrentando escrutinio público.

Dentro de este contexto son especialmente interesantes los trabajos de Rachel Whitered, Peter Eisenman y Jochen Gerz. Con: Memorial para el Holocausto en Viena, Memorial a los Judíos Muertos en Europa (Berlín) y Monumento contra el Fascismo (Hamburgo), respectivamente.

Ahora, como se mencionó con anterioridad, en Sudamérica la discusión sobre como recordar la aparición de los diferentes regímenes autoritarios que han existido en la región -con los consecuentes asesinatos, crímenes, abusos, etc.- es aún una tarea por cumplir. Pero incluso en este espacio restringido la práctica de la artista colombiana Doris Salcedo es particularmente relevante.

Este nuevo flujo de artistas y arquitectos se encuentra en búsqueda de nuevas preguntas y posibles soluciones al tema, no interesándose en respuestas dogmáticas que sienten las bases para una «correcta y contemporánea solución al problema», sino que en crear proyectos reflexivos ante él.

Personalmente creo es ésta también la intención de mi trabajo. A través del proyecto Memento ${ }^{16}$ he estado explorando diferentes modos de enfrentar la problemática que acarrean los distintos aspectos involucrados en el tema de la conmemoración en Chile, tanto desde su perspectiva fenomenológica así como de la inclusión de estos lugares en la ciudad. Así, algunos tópicos impresos en él son: la negociación entre un sentido de pérdida íntimo y la respuesta pública hacia éste, la idea de una historia en constante evolución (manera

13 El Memorial Nacional de la ciudad de Oklahoma fue creado después del bombardeo en 1995 del edificio federal Alfred P. Murrah en Oklahoma, USA.

14 El proceso de creación de este memorial fue particularmente controversial. Cuando el «entonces presidente Clinton compara el sitio a un campo de guerra» y a Gettysburge «todos lugares marcados por el sacrificio por la libertad». La retórica encontró un enemigo elocuente en la persona de Pam Whicher, la viuda de un agente secreto que murió en el lugar... "yo creo que sanaríamos mejor si aceptáramos la verdad». Whicher escribió luego: «esto no es nada más que un maldito desperdicio inútil de vidas». En: Kirk Savage. Trauma, healing: The therapeutic monument. Public Art Review 2006; 35:p. 42 (traducción libre del autor).

15 Irma Muller, madre del detenido desaparecido Jorge Muller Silva (detenido en noviembre 29, 1979). En: Marjorie Agosín. Tapestries of hope,threads of love. Albuquerque: University of New Mexico Press, 1996; p. 128 (traducción libre del autor).

16 Como el proyecto no podía ser llamado «memorial», tampoco «monumento» o «antimonumento». La decisión fue llamarlo Memento: imperativo del verbo recordar. Y que tiene también un significado similar a la palabra recuerdo (como objeto). Así, se compone por una acción (recordar), un sujeto (obra-observador) y un tiempo (instante-ahora). Es finalmente un evento en un fragmento de espacio y tiempo. 
Memento I instalaciones. Autor: Claudia Renedo Skarneo. Instalaciones realizadas en Greenwich, Londres, utilizando mobiliario abandonado encontrado en los mismos basureros del lugar. Serie fotográfica de 7 escenas íntimas recreadas en las calles.
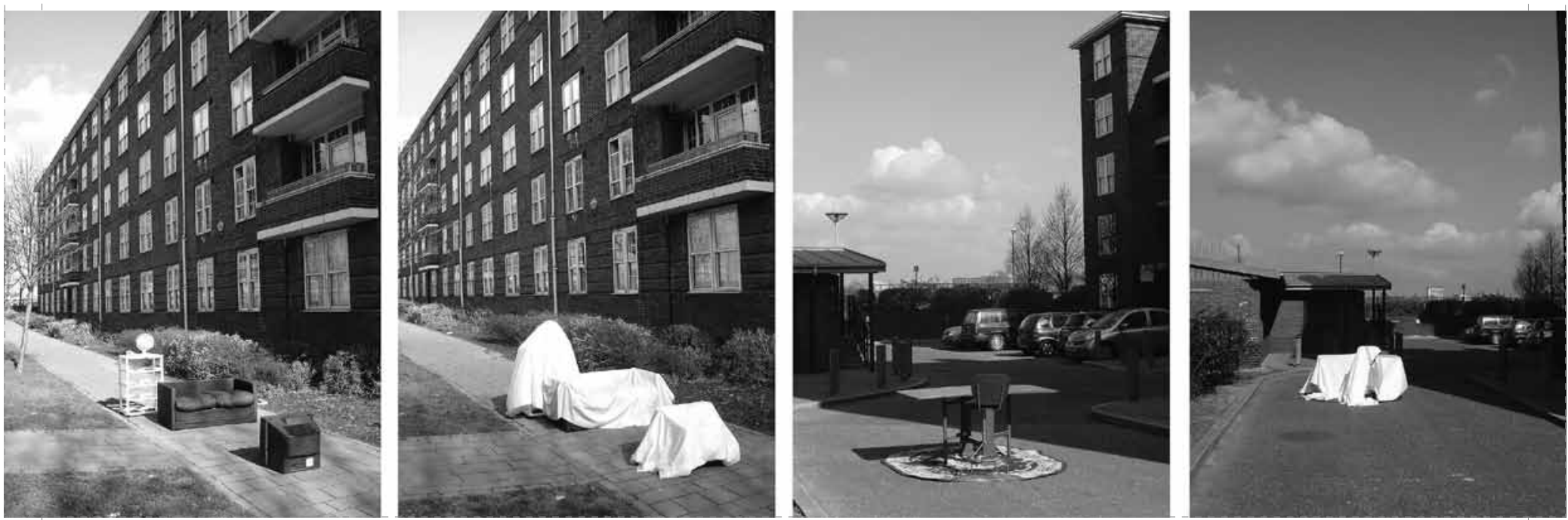

de recordar) más que una concepción fija de eventos, el reconocimiento de estar trabajando con una temática que sólo puedo atisbar desde lo ajeno y finalmente la problemática espacial que plantea el desarrollar una serie de intervenciones urbanas temporales que se involucran en y con la ciudad simbióticamente, vale decir generando relaciones de mutua dependencia en donde el soporte contextual y el contenido sean capaces de adaptarse a las realidades físicas, ambientales y sociales contingentes. Así este proyecto de conmemoración encontraría su lugar físico en el tejido urbano propio de la vida cotidiana íntima y rutinaria del ciudadano. En vez de manifestarse grandilocuentes en plazas, accesos y/o avenidas, aparecen por momentos en la vuelta de la esquina, en la calle comercial, en la fachada de la casa del vecino. Un cambio de memorial-hito-monumento a memento-cotidiano-fragmento. Cabe aclarar, de todas maneras, que Memento no es la respuesta, es más el punto de partida para un nuevo grupo de preguntas y experimentos. Es por esto que el proyecto en sí mismo es una secuencia de piezas o mementos (Memento I, II y (II), y no una respuesta final y única. Me gusta pensar que luego aparecerá Memento IV -y más- continuando con la arqueología por respuestas.

Volviendo a los ejemplos citados con anterioridad, estos han re-concebido el rol de memoriales y monumentos; o de acuerdo con
James E. Young, han eludido las trampas que fácilmente emergen al materializar memoria. Quizás la contribución más significante de estas obras -y donde encuentran su punto en común- es que «cambian el énfasis de la remembranza desde el monumento hacia el espectador ${ }^{17}$, creando un proceso de re-significación evolutivo siempre a cargo de la experiencia individual. Esto es, de alguna manera, el opuesto al estado fijo de los monumentos y memoriales que vimos en la primera parte del documento.

\section{Por supuesto que estos nuevos lugares} estudiaron una manera formal de ser y hacer el memorial (aparecer visible); sin embargo, con la intención de «dejar al espectador llevar la carga de la remembranza» ${ }^{18}$, buscaron cómo enseñar también lo que es invisible, preguntando por la manera para re-presentar lo ausente y motivando a la audiencia a sus propias conclusiones. El Memorial al Holocausto en Viena (Rachel Whiteread) y e Monumento en contra el Fascismo (Jochen Gerz) son particularmente expresivos sobre esto. En el primer caso, Whiteread nos enseña como incluso la más concreta aparición de materialidad puede hablarnos sobre un vínculo perdido, sobre una ausencia. Así, haciendo uso de la metáfora del libro como principal instrumento de transmisión a través de la historia; se revela el vacío infinito que el moldelomo no legible del libro nos hace enfrentar. Sólo el vacío -que la terrible masacre del holocausto dejó tras nuestro- es lo que permanece.

El segundo caso, Monumento en contra el Fascismo de Jochen Gerz, posee incluso un nombre alternativo: «El Monumento que Desaparece». El primer problema con que Gerz se encontró fue: «¿cómo se hace un monumento en contra de algo?» ${ }^{19}$. 0 peor aún: ¿cómo crear un monumento antifascista sin re-llamar a lo que él reconoció como una tendencia fascista en todos los monumentos?20. Y aparentemente su respuesta fue hacerlo desaparecer, literalmente. Pidiendo colaboración pública en el proceso:

«Invitamos a los ciudadanos... a añadir sus nombres aquí junto a los nuestros. A hacerlo, nos comprometemos a permanecer vigilantes. Mientras más y más nombres cubren esta columna de fierro de 12 metros, ésta comenzará gradualmente a enterrarse en el suelo. Algún día habrá desaparecido completamente y el lugar del monumento en contra el fascismo estará vacío. Al final, somos sólo nosotros mismos quienes podemos plantarnos en contra de la injusticia» 21 .

En mis propuestas, la aparición de lo ausente se encuentra en el espacio existente entre el objeto y su proyección en la pared. Es un vacío concreto, puesto que se puede medir; es espacio en sí mismo, es la nada que hace la proyección posible. Pero es también

\footnotetext{
David Dibosa. Witness this: Art, memory, democracy. Parachute 111. Québec: Parachute, 2003; p. 91 (traducción libre del autor).

Ibid, p. 91 (traducción libre del autor).

Jochen Gerz, en: [http://www.gerz.fr] (traducción libre del autor)

20 James E. Young. At memory's edge. Londres: Yale University Press, 2000; p. 130 (traducción libre del autor)

21 Inscripción temporal en la base del monumento. En: James E. Young. At memory's Edge. Londres: Yale University Press, $2000 ;$ p. 130 (traducción libre del autor).
} 

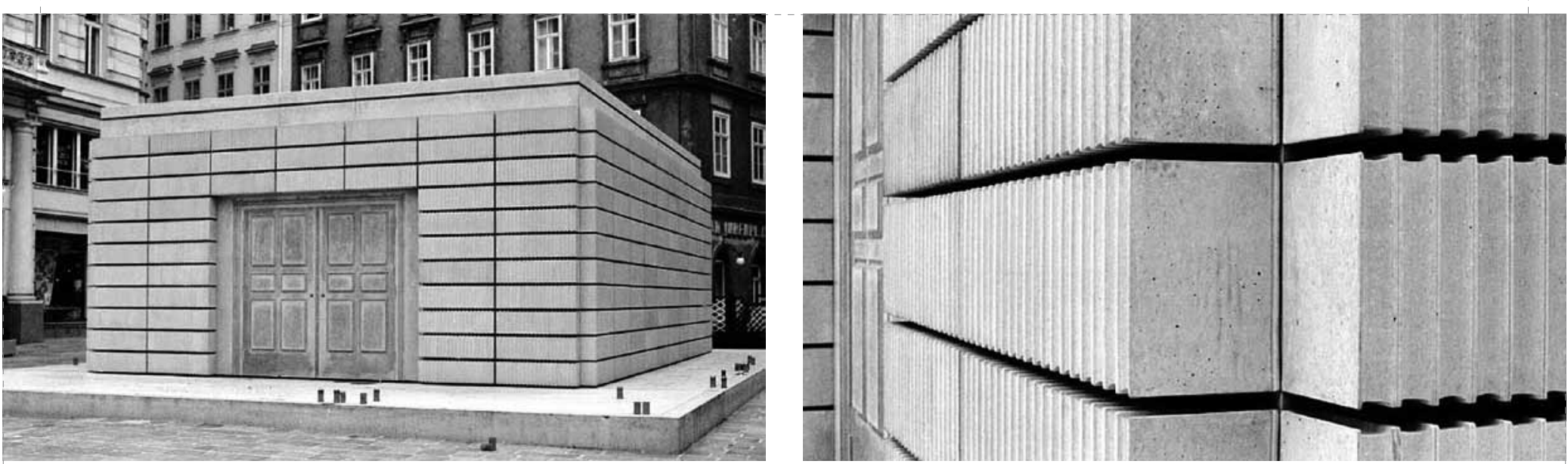

Memorial al Holocausto en Viena. Autor: Rachel Whiteread. Fuente: University of South Carolina Archives
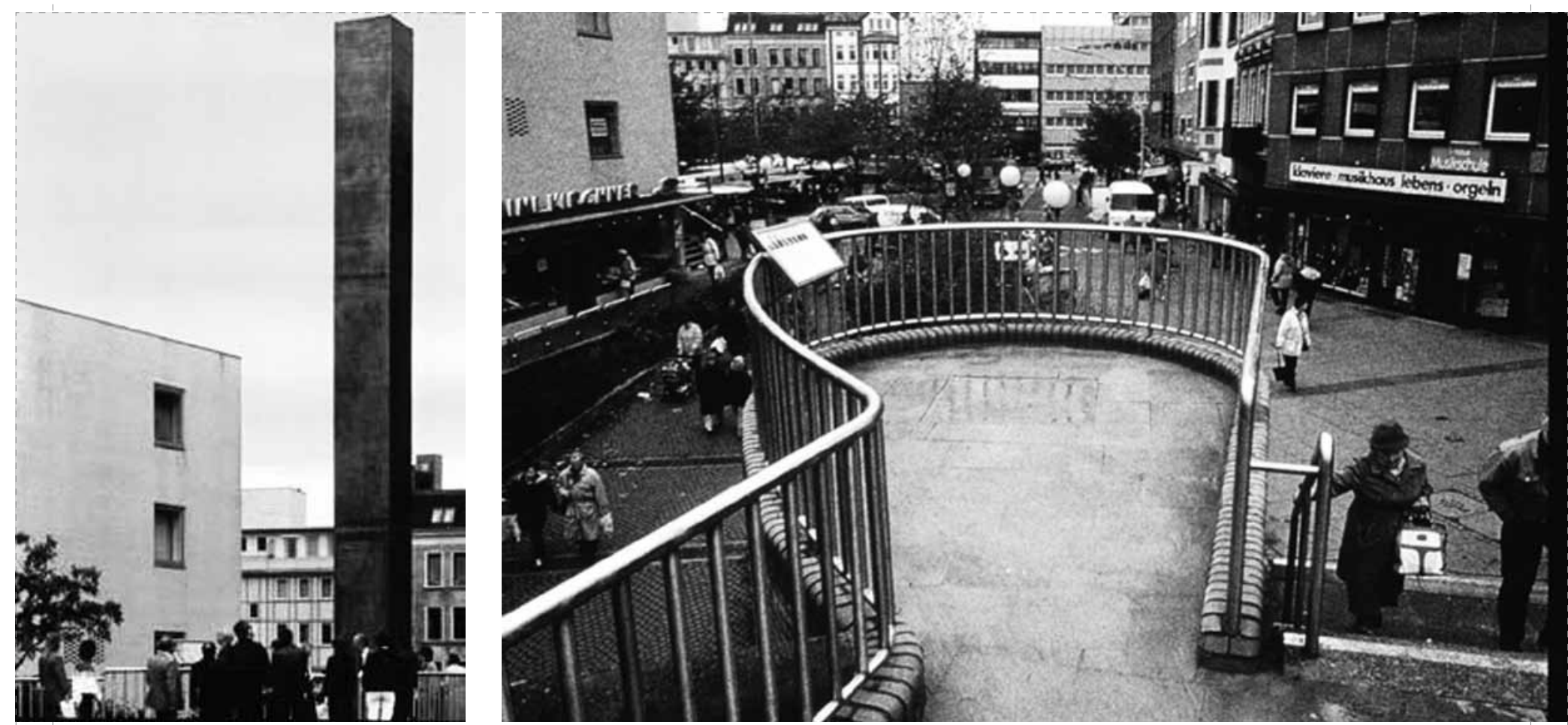

Monumento contra el Fascismo. Autor: Jochen Gerz. Fuente: www. shalev-gerz.net

una ausencia más compleja, ya que hace evidente la brecha que existe entre mi persona -como autor-y el evento que está siendo narrado. Es también la fisura entre los estados alterados del relato y los diferentes niveles de abstracción que el evento va sufriendo con el paso del tiempo.
Otro desafío importante que artistas y diseñadores han enfrentado es el romper la aparente inmutabilidad de monumentos y memoriales. Un interesante ejemplo sobre esto es el Memorial a los Judíos de Europa, de Peter Eisenman. En él, el enfoque hacia el desafío es completamente diferente. Peter
Eisenman a través del diseño de una plaza le permite a los visitantes experimentar el lugar tal como lo haría en cualquier otro espacio público de la ciudad; reconociendo las maneras de caminar, descansar e incluso divertirse: 

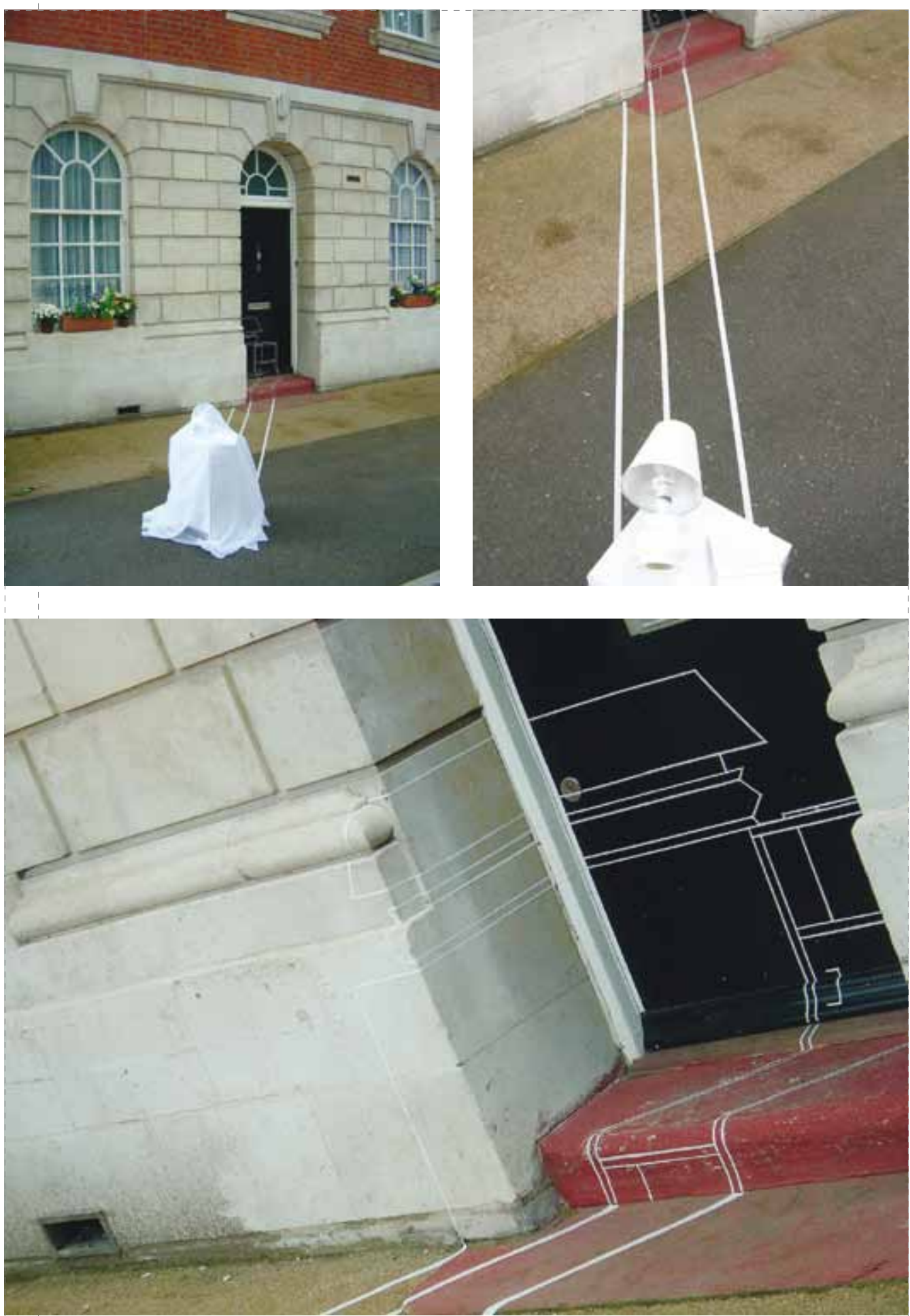

Memento 1I: Escena velador. Autor: Claudia Renedo Skarneo. Serie de dos instalaciones realizadas en Millbank, Londres. Utilizando la fachada de una vivienda como soporte de proyección y la creación de 2 escenas, un velador y un comedor. Mientras la materia en sí se presenta en caos, el dibujo proyectado en la pared se presenta en orden, pero asumiendo las geometrías de la vivienda soporte, lo que finalmente implica la deformación del dibujo que sólo puede ser visto en su origen desde una posición en particular. Ambas instalaciones aparecen por un fin de semana para luego desaparecer.
«Donde lo 'monumental' ha generalmente utilizado su tamaño para humillar o intimidar a los observadores en sumisión, este memorial en sus humanamente proporcionadas formas situaría a las personas en un punto de igualdad con la memoria. Los visitantes y el rol que juegan mientras caminan de rodillas, o con el pecho en alto, o recogidos de hombros entre este campo oleado de piedras, no se verán disminuidos por lo monumental sino que se harán parte integral del memorial, ahora invitados como iguales ante el diálogo de la memoria ${ }^{22}$.

La participación del espectador en el último caso es fundamental, y la libertad con que este puede vivir el lugar es extraordinaria, pero cómo la gente habita ese espacio está estrictamente relacionado con las características del lugar. De algún modo, la audiencia sigue atrapada por los límites de este espacio público memorial y sus experiencias y posibles reflexiones sobre el asesinato de judíos están circunscritos también en él. Con Memento, también apelo a la participación pública, pero la aparición y desaparición del proyecto ocurre repentinamente: en un momento y lugar cuando/donde el paseante no espera encontrarlo. Así, el contexto alrededor juega un rol importantísimo en esta interrupción inesperada de la rutina diaria -mientras que el mismo contexto muestra el transcurso de ésta-. En Memento hay «azarosidad» entre lo aparecido y lo desaparecido, el dibujo anamórfico mostrando y ocultando su significancia de lo oculto ${ }^{23}$ Esto puede ser explicado también como la yuxtaposición entre lo racional y lo irracional -una manera muy humana de enfrentar eventos y recuerdos dolorosos-.

22 James E. Young Op. cit. p. 210 (traducción libre del autor).

23 «La anamorfosis... juega a causar estragos con elementos y principios; en vez de reducir las formas por a sus límites visibles, los proyecta más allá de ellos mismos y los distorsiona de manera tal que vistos desde un punto espacial específico vuelven a su forma original... Implica una poesía de la abstracción, un mecanismo efectivo para provocar ilusiones ópticas, y una filosofía de la falsa realidad”. En: Jurgis Baltrusaitis. Anamorphic Art. Cambridge: Chadwyck-Healey Ltd., 1977; p. 1 (traducción libre del autor).

Un dibujo anamórfico hace que las imágenes aparentes desaparezcan mientras que al mismo tiempo aparecen las líneas ocultas según la participación del observador. Hasta el siglo xvII las técnicas para crear este tipo de dibujos se guardaron celosamente en secreto, por lo que siempre han acarreado un fuerte contenido político de lo oculto. 
Memorial a los judíos de Europa. Autor: Peter Eisenman.
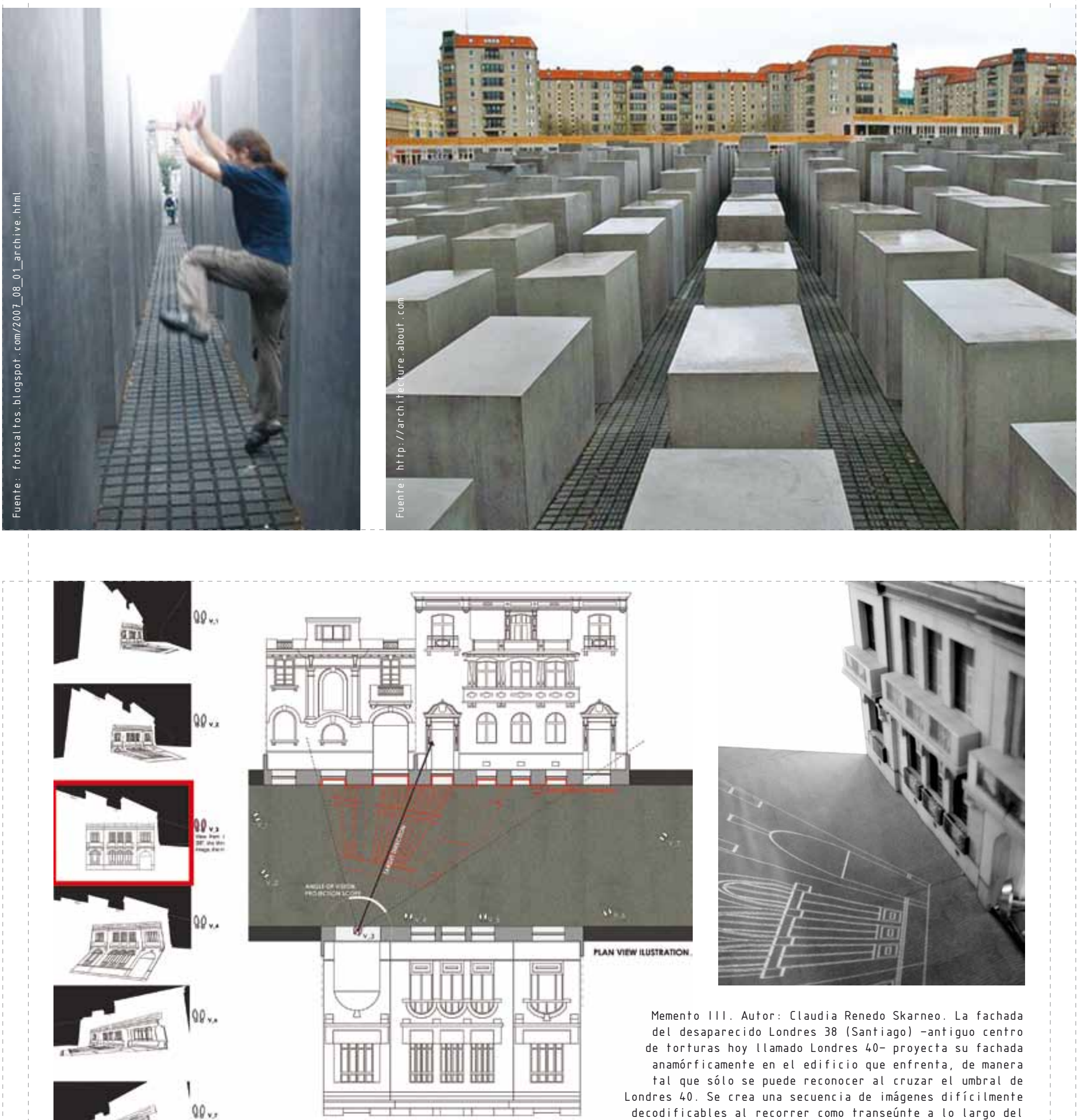

Memento 111. Autor: Claudia Renedo Skarneo La fachada del desaparecido Londres 38 (Santiago) -antiguo centro de †orturas hoy llamado Londres 40 - proyecta su fachada anamórficamente en el edificio que enfrenta, de manera tal que sólo se puede reconocer al cruzar el umbral de Londres 40 . Se crea una secuencia de imágenes difícilmente decodificables al recorrer como transeúnte a lo largo de

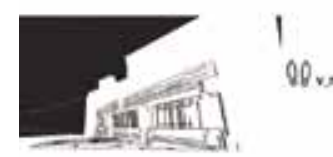

barrio París-Londres. 


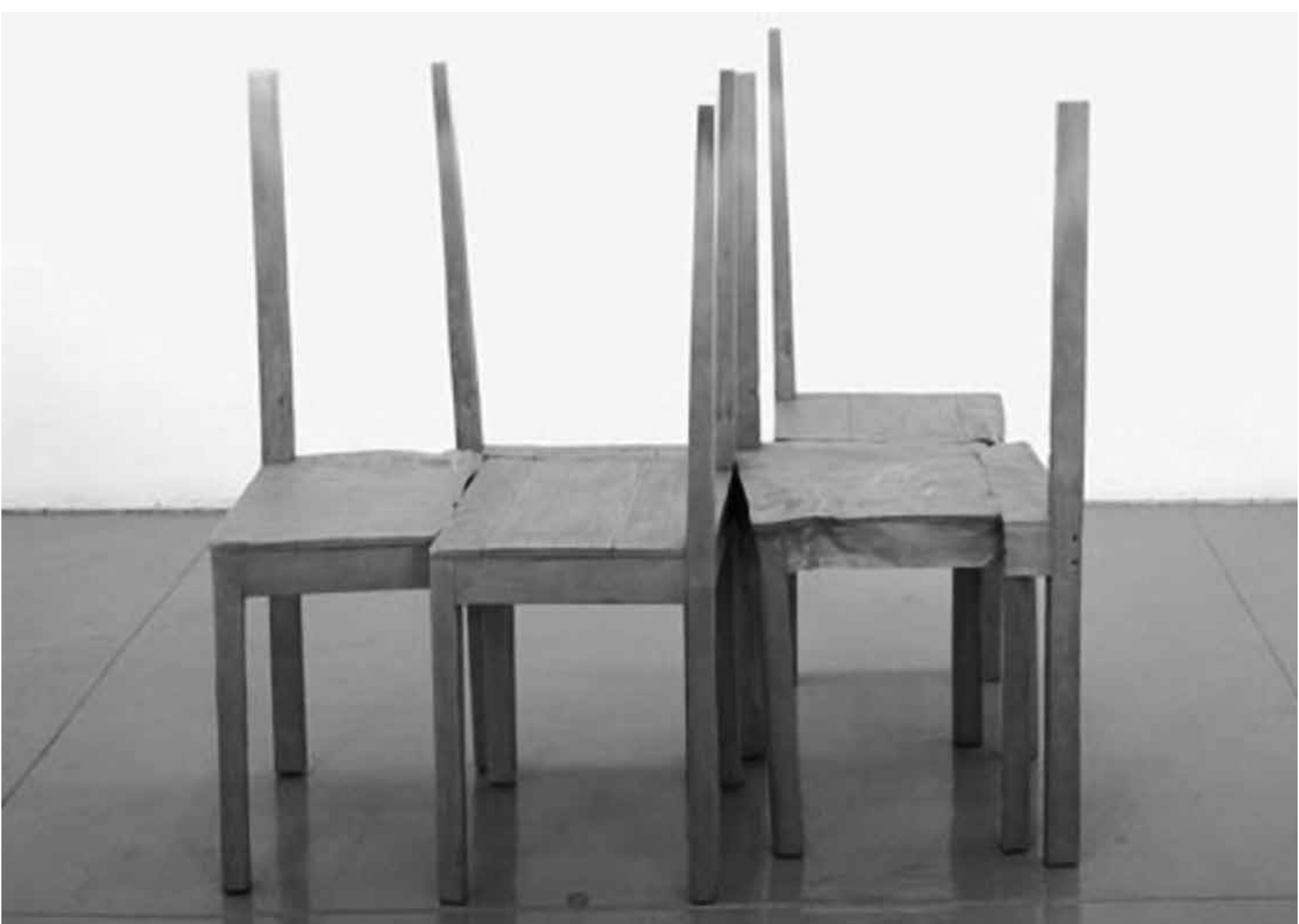

Por su parte, la artista colombiana Doris Salcedo, quien coincidentemente fracturó el Hall de las Turbinas en el Tate Modern en Londres recientemente, ha desarrollado su trabajo en relación con eventos traumáticos en su país desde hace un buen tiempo ya. Usualmente utiliza muebles o piezas de género que han sido criminalizadas para demostrar la violencia y su incidencia en la esfera social. A través de esta chocante narrativa busca transformar la experiencia privada de las víctimas en experiencias colectivas de reflexión sobre la sensación de injusticia y terror en su país y en contexto con el resto del mundo. Bajo un punto de vista crítico su trabajo puede ser fácilmente definido como extremadamente emocional, nostálgico y pasional.
Personalmente creo que su obra es emocional, nostálgica y pasional, tal como -reconozcoMemento (especialmente Memento II) se puede definir. Pero: ¿no es acaso el asunto con el que se trabaja extremadamente emocional? ¿Debería la capacidad humana para: sentir miedo, tristeza, rabia e incluso vergüenza ante el horror de este tipo de violencia ser censurada para lograr una obra más neutra o intelectual? No pretendo responder a estas preguntas; quedarán planteadas para un futuro. Lo que pretendo es promover maneras de pensar que «impliquen tomar posesión de la historia. Historia que cesa de ser el tiempo de un otro... cesa de ser el espacio de otro; conmemoración que cesa de ser la responsabilidad de otro» ${ }^{24}$.

\section{Сіегге}

Finalmente, el desafío aquí es enfrentar la inmensa problemática que acarrea el diseño de espacios para la conmemoración, rehuyendo la imposición clásica existente en la materia. Creo que monumentos y memoriales han de transformarse en espacios reflexivos donde el cambio histórico debería manifestarse, incluso si esto finalmente significa la muerte del monumento, la decadencia de la materia. Si esto ocurre, el proceso de la remembranza tomará un curso distinto; no como una huella de poder en un cierto espacio público sino que como una huella de pérdida en un cierto mundo íntimo.

24 David Dibosa. Op. cit.; p. 92 (traducción libre del autor). 
Proyecto Tenebrae (7 noviembre 1985). Autor: Doris Salcedo. Fuente: www. whitecube.com

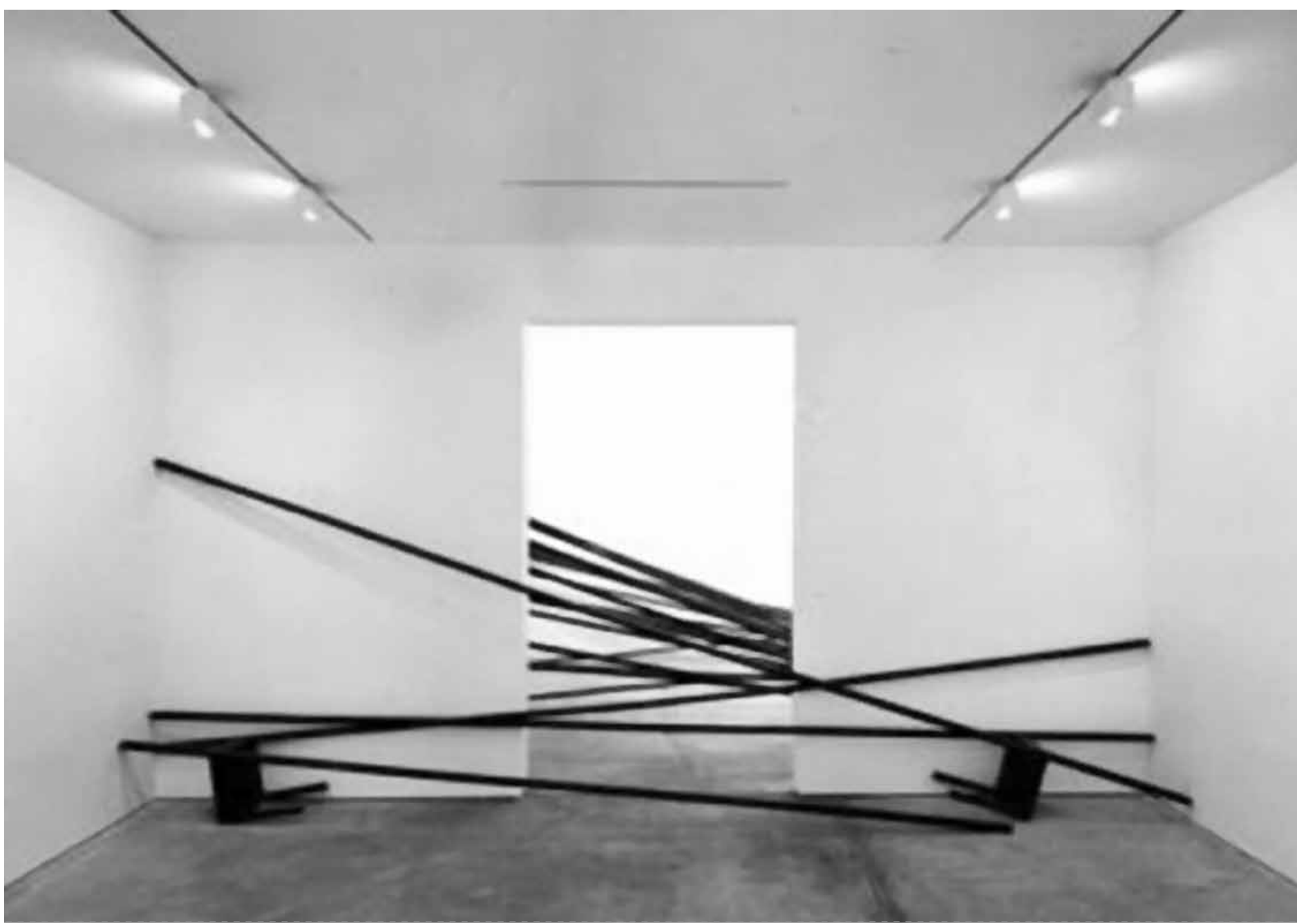

\section{Bibliografía}

- Marjorie Agosín. Tapestries of hope, threads of love. Albuquerque: University of New Mexico Press, 1996

- Jurgis Baltrusaitis. Anamorphic art. Cambridge: Chadwyck Healey Ltd, 1997.

- Andrew Benjamin. Object. Painting. Londres: Academy Editions, 1994

- Henri Bergson. Matter and memory. New York: Zone Books, 1988

- David Cottington. Modern art. A very short introduction. Oxford: Oxford University Press, 2005.

- Adrian Forty, Susanne Kuchler. The art of forgetting. Oxford: Berg, 1999

- E.H. Gombrich. The image and the eye. Oxford: Phaidon, 1982.

- Henri Lefebvre. The production of space. Oxford: Blackwell, 1991.

- Sébastien Marot. Sub-urbanism and the art of memory. Londres: AA, 2003.
- M. Merleu-Ponty. Phenomenology of perception. New Jersey: Humanities Press, 1962.

- George Perec. A void. Londres: The Harvill Press, 1995.

- Rachel Whiteread. Londres: Haunch of Venison, 2002.

- Paul Ricoeur. Memory, history, forgetting. Chicago: The University of Chicago Press, 2004

- $\quad$ Lyons Roth, Merewether. Irresistible decay. Los Ángeles: Bibliographies \& Dossiers, 1997.

- Marita Sturken. Tangled memories. Londres: University of California Press, 1997.

- Marita Sturken, Lisa Cartwright. Practices of looking: An introduction to visual practice. Oxford: Oxford University Press, 2001

- Bernard Tschumi. Architecture and disjunction. Londres: The MIT Press, 1996.

- Anthony Vidler. Warped space. Londres: The MIT Press, 2001
- Brian Wallis. Art after modernism: Rethinking representation. New York: The New Museum of Contemporary Art, 1984

- James E. Young. At memory's edge. Londres: Yale University Press, 2000.

- James E. Young. The texture of memory. Londres: Yale University Press, 1993.

Revistas:

- Public Art Review 2006; 35.

- Harvard Design Magazine 1999; 9.

- The Structurist 1998; 37/38.

- The Architectural Review 2002

- Grand Street N 68

- Parachute 1112003.

Web:

- http://findarticles.com/

- http://en.wikipedia.org/

- http://vnweb.hwwilsonweb.com

- www.gerz.fr/

- www.cr.nps.gov/history/resedu/savage.htm 